\title{
EFEITO DE BORDA NO INVENTÁRIO DOS MACIÇOS DE EUCALIPTO DO PARQUE IBIRAPUERA POR MEIO DO USO DE SENSORIAMENTO REMOTO E GEOPROCESSAMENTO
}

\author{
Demóstenes Ferreira da Silva Filho ${ }^{1}$, Ana Paula Beber Veiga ${ }^{2}$, Jefferson Lordello Polizel ${ }^{3}$, \\ Hilton Thadeu Zarate do Couto ${ }^{4}$, João Luís Ferreira Batista ${ }^{5}$
}

\section{RESUMO}

Este trabalho avaliou os maciços de eucalipto do Parque Ibirapuera para conhecer o efeito proporcionado pela proximidade da vegetação do parque com o ambiente urbano da cidade de São Paulo. Por meio do uso de imagens aerofotogramétricas e inventário dos maciços de eucalipto e georreferenciamento em sistema de informação geográfica (SIG) obtiveram-se estimativas e medidas que comprovaram o efeito de borda, por meio de diagramas de dispersão e equações de regressão, a relação entre a distância dos maciços do perímetro ou do centro do parque e o estado de conservação das árvores constituintes dos oito maciços. Os resultados comprovaram a necessidade de intervenção para a substituição gradual da vegetação próxima das avenidas e estabelecimento de novos maciços.

Palavras-chave: Parque urbano, Silvicultura urbana, Sensoriamento remoto, SIG

\footnotetext{
${ }^{1}$ Engenheiro Agrônomo, professor na Universidade de São Paulo junto a Escola Superior de Agricultura "Luiz de Queiroz", Departamento de Ciências Florestais, dfsilva@esalq.usp.br ${ }^{2}$ Engenheira Florestal, graduanda de Gestão Ambiental da unidade USP LESTE, anapbveiga@hotmail.com

${ }^{3}$ Analista de Sistemas, mestrando em Geografia Física na Universidade de São Paulo, Departamento de Geografia, jlpolize@esalq.usp.br

${ }^{4}$ Engenheiro Agrônomo, professor titular na Universidade de São Paulo junto a Escola Superior de Agricultura "Luiz de Queiroz", Departamento de Ciências Florestais, htzcouto@esalq.usp.br ${ }^{5}$ Engenheiro Florestal, professor na Universidade de São Paulo junto a Escola Superior de Agricultura "Luiz de Queiroz", Departamento de Ciências Florestais, jlfbatis@esalq.usp.br
} 


\title{
BORDER EFFECT ON INVENTORY OF EUCALYPTUS DENSE FOREST AT \\ IBIRAPUERA PARK USING REMOTE SENSING AND GEOPROCESSING
}

\begin{abstract}
This work evaluated the Ibirapuera park eucalyptus forest to know the effect provided by the proximity of the park vegetation with São Paulo city urban atmosphere. By means of the use of aerofotogrametric images and eucalyptus inventory and georeferencing in geographical information system (GIS) they were obtained estimates and measures that checked the border effect by means of dispersion diagrams and regression equations, the relationship among the distance of the park perimeter trees or center trees and their state of conservation. The results checked the intervention need for the gradual substitution of the close vegetation near to the avenues and establishment of new group of trees.
\end{abstract}

Key-words: Urban parks, Urban Forestry, Remote sensing, GIS 


\section{INTRODUÇÃO}

Os parques urbanos são espaços públicos com dimensões significativas e predominância de elementos naturais, principalmente cobertura vegetal, destinados à recreação (KLIASS, 1993).

O Parque Ibirapuera situa-se dentro da cidade de São Paulo no bairro de mesmo nome, na Avenida Pedro Álvares Cabral s/n. Inaugurado em 21 de agosto de 1954, nas comemorações dos 400 anos da cidade de São Paulo, o Ibirapuera é um dos parques mais procurados pela população paulistana, apresentando freqüência média de 300 mil usuários por semana em uma área de um milhão e cem mil metros quadrados, sendo assim, uma das mais importantes áreas verdes da cidade e local permanente de cultura e lazer (VEIGA, 2004).

O parque possui uso intensivo por parte da população local, durante a semana e de toda a cidade, principalmente no final de semana.

Até recente data, a maioria dos estudos sobre conservação arbórea se preocuparam com as florestas ou outros habitats (semi-naturais), não havendo estudos sobre parques urbanos. Uma das razões é a de que os parques possuem objetivos multifuncionais, sendo a conservação biológica apenas uma pequena, mas crescente preocupação (HERMY \& CORNELIS, 2000).

Os maciços de eucalipto são a vegetação arbórea de maior porte e mais antiga do Parque Ibirapuera. Foram plantadas, provavelmente, no final da década de vinte e início da década de trinta com intuito de melhorar as condições de drenagem da área.

O ambiente urbano não é apropriado ao ciclo de vida das árvores plantadas. Os inconvenientes têm sua origem na ação de agentes bióticos e abióticos. A ação antrópica pode causar danos diretos por meio de ferimentos, ou indiretos, pela poluição e manejo inadequados. Como resultados, poderão ocorrer desde pequenas lesões, até a morte dos indivíduos mais afetados (AUER, 1996).

O conceito de declínio, como uma terceira categoria de problema fitossanitário associado às árvores, trouxe uma nova compreensão sobre a avaliação da condição e conseqüente tratamento fitossanitário para as árvores na cidade. A síndrome do declínio é entendida, então, como causada pela interação de fatores bióticos e abióticos, especificamente ordenados e inter-relacionados, produzindo uma deterioração geral e gradual da sanidade do indivíduo, culminando com sua morte (MILANO \& DALCIN, 2000)

O conceito de borda compreende o perímetro de um fragmento florestal, uma paisagem, um lago. Enfim, é a linha que contorna toda a parte externa de um polígono, independemente da forma que este possui (quadrado, círculo ou outra forma qualquer geometricamente indefinida). Importante não confundir o conceito de borda com o de 
ecótono - que é uma região de transição entre dois ecossistemas diferentes ou entre duas comunidades (SILVA, 2004).

O parque Ibirapuera é circundado por avenidas que possuem trânsito intenso, ruído e poluição do ar que provavelmente afetam o parque, sobretudo a biota próxima de sua borda.

Do ponto de vista funcional, as bordas são espaços onde a intensidade dos fluxos biológicos entre unidades de paisagem se modifica de forma abrupta (METZGER, 1999).

O conceito de efeito de borda é definido como o aumento da variedade e densidade das populações de algumas espécies na zona do ecótono (interface entre duas comunidades ou ecossistemas), em comparação com o que ocorre na zona central do ecossistema ou comunidade a que elas pertencem originalmente (SILVA, 2004).

Com intuito de avaliar o efeito do ambiente urbano sob as árvores do parque a pesquisa foi estruturada pelo inventário das condições de vigor e sanitárias de oito maciços de eucalipto remanescentes dos primeiros plantios e provavelmente são as árvores indicadoras das relações entre a poluição, excesso de luminosidade noturna, calor urbano e a vegetação do parque.

\section{MATERIAL E MÉTODOS}

\section{Avaliação quali-quantitativa dos maciços do Parque Ibirapuera}

$\mathrm{Na}$ coleta de dados dos indivíduos arbóreos foi usada planilha adaptada de SILVA FILHO, (2002) (Figura 1), baseada em observações visuais no local, e na coleta de parâmetros dendrométricos utilizando-se uma fita métrica (medição do CAP) e hipsômetro de Blume-leiss (medição da altura da $1^{a}$ ramificação e altura geral). 


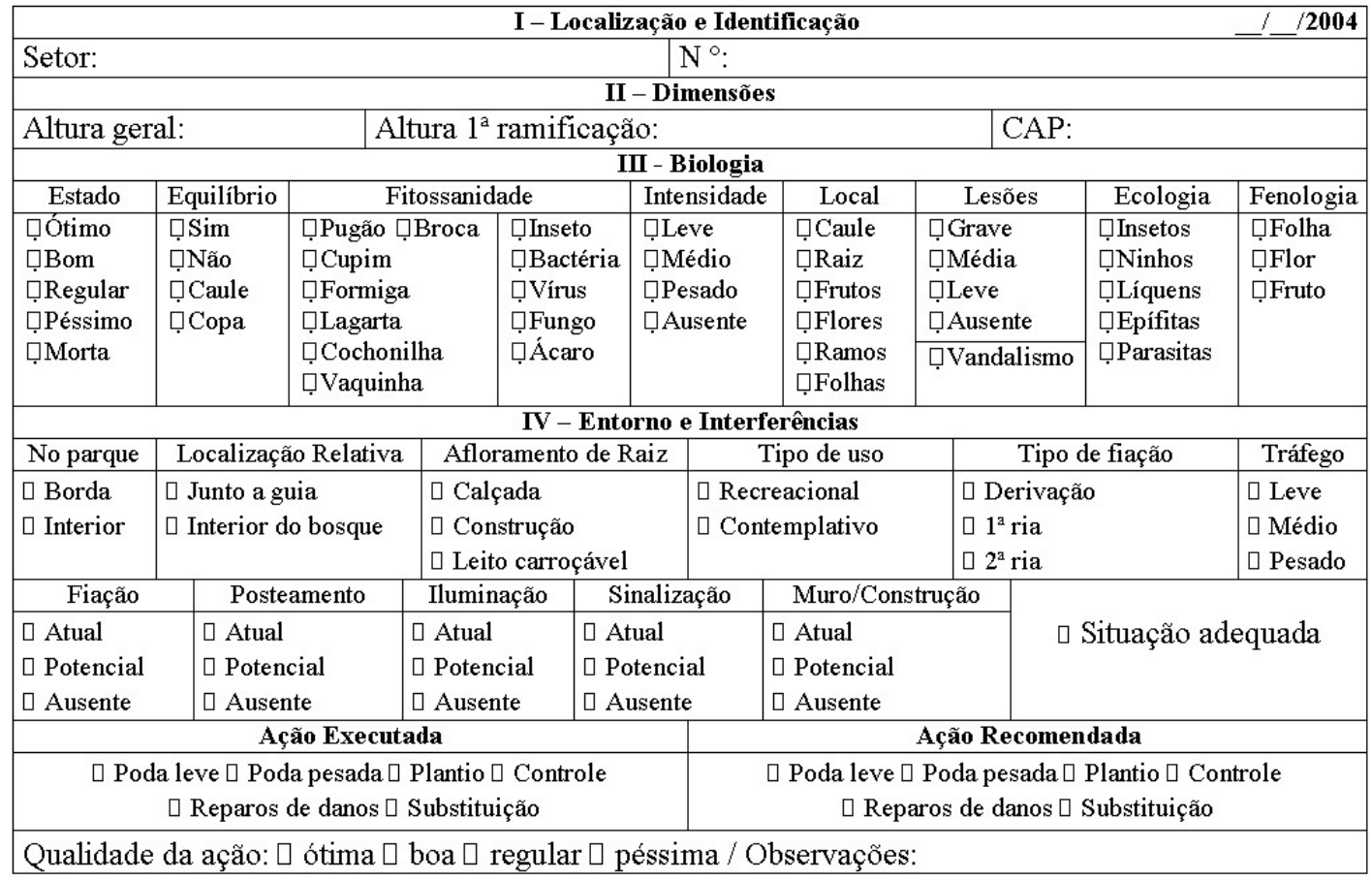

Figura 1. Ficha para coleta dos dados no campo

Segundo o mesmo autor, alguns itens analisados são subjetivos, tornando sua descrição necessária.

\section{a) Estado geral}

Ótimo: árvore vigorosa e sadia; sem sinais aparentes de ataque de insetos, doenças ou injúrias mecânicas; pequena ou nenhuma necessidade de manutenção; forma ou arquitetura característica de espécie.

Bom: médias condições de vigor e saúde; necessita de pequenos reparos ou poda; apresenta descaracterização da forma; apresenta sinais de ataque de insetos, doença ou problemas fisiológicos.

Regular: apresenta estado geral de início de declínio; apresenta ataque severo por insetos, doença ou injúria mecânica, descaracterizando sua arquitetura ou desequilibrando o vegetal; problemas fisiológicos requerendo reparo.

Péssimo: avançado e irreversível declínio; apresenta ataque severo por insetos, doença ou injúria mecânica, descaracterizando sua arquitetura ou desequilibrando o vegetal; problemas fisiológicos cujos reparos não resultarão em benefício para o indivíduo.

Morta: árvore seca ou com morte iminente.

b) Equilíbrio geral: quando a árvore possui caule reto e copa de mesmas proporções para todos os lados.

c) Intensidade (de fitossanidade)

Leve: quando o organismo ou agente está presente, porém sem causar danos á arvore. 
Médio: quando o organismo ou agente está presente, causando danos reparáveis à árvore.

Pesado: quando o organismo ou agente está causando danos graves, que podem levar a árvore a um declínio irreversível.

d) Injúrias

Grave: quando a lesão compromete a sobrevivência da árvore.

Média: quando a injúria é considerável, mas a árvore pode ser recuperada mediante ações de controle.

Leve: quando a injúria é de pequena proporção e a árvore pode promover a recuperação sem qualquer auxílio.

e) Tráfego

Leve: poucos veículos (de 0 a 10) passaram na via pública durante o momento de cadastro na rua.

Médio: Quando alguns veículos (de 0 a 20) passaram pela via pública durante o momento do cadastro.

Pesado: quando mais de 20 veículos passaram na via pública durante o momento do cadastro.

f) Situação adequada: quando a árvore está bem no local, em relação a conflitos com outros equipamentos ou construções.

g) Fiação, Posteamento, Iluminação, Sinalização e Muro/Construção

Atual: quando o equipamento urbano ou edificação está em contato com alguma parte da árvore.

Potencial: quando a espécie, pelo seu crescimento normal, vai entrar em contato com algum equipamento ou edificação.

Ausente: quando não existir possibilidade de contato.

h) Qualidade da ação

Ótima: ação correta, necessária para adequada manutenção da árvore, executada com técnica.

Boa: ação correta, porém sem técnica.

Regular: ação executada sem a observância e normas técnicas, porém sem causar danos graves.

Péssima: ação incorreta, com conseqüências graves para a árvore.

Além dessas avaliações foi aplicado o resistógrafo nos maciços 1,2,3,4 e 5 em uma árvore para cada maciço. O resistógrafo foi posicionado na base do caule e acionado até atravessar a árvore registrando-se a leitura em papel especial. 


\section{Determinação dos diferentes elementos do parque e sua medição}

Foram identificados os elementos presentes na configuração atual do parque. As medições foram feitas usando fotografia aérea georeferenciada recente do local de estudo. Para o georreferenciamento das fotografias aéreas primeiramente foi confeccionado um mosaico das nove fotos cedidas pela administração do parque e em seguida foram coletados treze pontos, dentro e no entorno do parque, utilizando o GPS GARMIN GPSMAP. Na configuração do GPS foi utilizado o Elipsóide WGS 84 e o DATUM WGS84. Com auxílio do software TNTmips, procedeu-se o georreferenciamento da fotografia do parque. Após essa etapa foi realizada, no mesmo software, uma classificação supervisionada usando algoritmo stepwise linear. Depois do mosaico e da classificação prontos, foi mensurada a área dos elementos do parque (Figura 2).

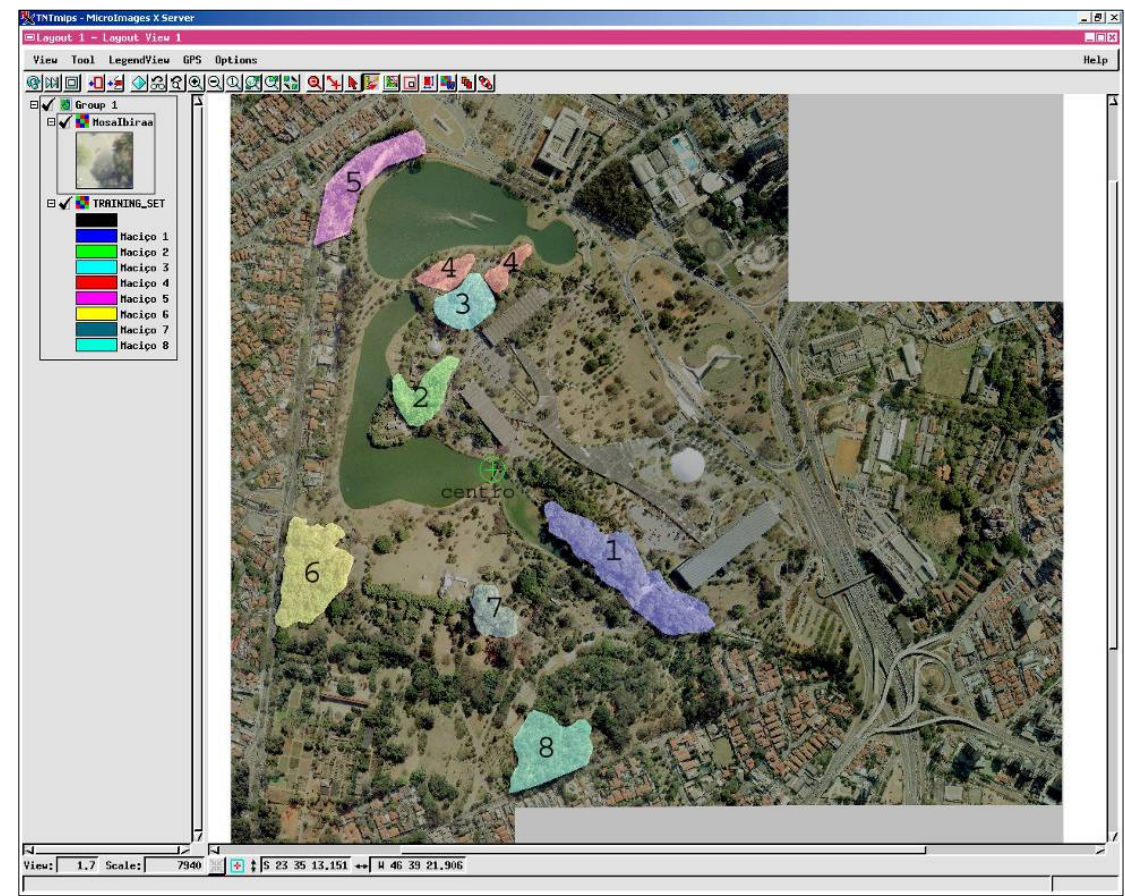

Figura 2. Mosaico das fotografias mostrando os maciços dentro do ambiente do SIG.

\section{RESULTADOS E DISCUSSÃO}

\section{Estudo dos maciços de Eucalipto do Parque Ibirapuera}

As espécies de Eucalipto plantadas no parque são: Eucalyptus camaldulensis, E cinerea, E. citriodora, E.goniocalix, E.resinifera, E. robusta, Eucalyptus spp. DEPAVE-CPHN (1988).

Foram estudados no total 8 maciços, dos quais nos três primeiros foi realizado o censo dos indivíduos e nos restantes, optou-se pela realização de amostragem sistemática, com intensidade amostral de um a cada dez indivíduos (1:10) e erro desejado de 15\%. 
Para os maciços onde foi realizado o censo a análise estatística foi feita de forma percentual, já para os maciços onde foi realizada a amostragem inicialmente foi definida como variável principal a altura geral das árvores cadastradas e, uma vez que a amostragem foi suficiente, a partir daí foi realizada a análise das variáveis qualitativas, também de forma percentual, e para isso, aceitando que a amostra tomada representa a população do maciço.

Foram cadastrados 278 indivíduos no maciço 1, 156 no maciço 2, 169 no maciço 3, 30 no maciço $4(\mathrm{~N}=302), 50$ no maciço $5(\mathrm{~N}=500), 31$ no maciço $6(\mathrm{~N}=315), 7$ no maciço 7 ( $\mathrm{N}=74), 42$ no maciço $8(\mathrm{~N}=429)$.

Como resultado da análise estatística realizada para as variáveis quantitativas a tabela 1 mostra os intervalos de confiança para cada variável de cada maciço.

Tabela 1. Intervalos de confiança e erro amostral para as variáveis quantitativas dos maciços amostrados 4, 5, 6, 7, e 8 .

\begin{tabular}{|c|c|c|c|}
\hline \multicolumn{2}{|c|}{ Maciços Amostrados } & Intervalo de Confiança & Erro Amostral* (\%) \\
\hline & Altura Geral & {$[27,02 ; 32,55]$} & 9,27 \\
\hline \multirow[t]{3}{*}{ Maciço 4} & Altura $1^{\mathrm{a}}$ ramificação & {$[5,88 ; 9,14]$} & \\
\hline & CAP & {$[1,26 ; 1,61]$} & \\
\hline & Altura Geral & {$[22,26 ; 28,95]$} & 13,07 \\
\hline \multirow[t]{3}{*}{ Maciço 5} & Altura $1^{\mathrm{a}}$ ramificação & {$[3,04 ; 6,00]$} & \\
\hline & CAP & {$[1,55 ; 1,94]$} & \\
\hline & Altura Geral & {$[31,10 ; 39,70]$} & 12,15 \\
\hline \multirow[t]{3}{*}{ Maciço 6} & Altura $1^{\mathrm{a}}$ ramificação & {$[5,98 ; 10,98]$} & \\
\hline & CAP & {$[1,80 ; 2,47]$} & \\
\hline & Altura Geral & {$[33,70 ; 41,00]$} & 9,77 \\
\hline \multirow[t]{2}{*}{ Maciço 7} & Altura $1^{\mathrm{a}}$ ramificação & {$[5,14 ; 10,65]$} & \\
\hline & CAP & {$[1,97 ; 3,07]$} & \\
\hline \multirow{3}{*}{ Maciço 8} & Altura Geral & {$[29,61 ; 36,39]$} & 10 \\
\hline & Altura $1^{\mathrm{a}}$ ramificação & {$[5,18 ; 9,96]$} & \\
\hline & CAP & {$[0,71 ; 5,24]$} & \\
\hline
\end{tabular}

*Erro amostral somente para a variável que foi definida como principal.

Quanto as dimensões das árvores cadastradas (Tabela 2), as árvores mais altas estão no maciço 7 e superam, em média os 37,36 metros de altura, enquanto as menores árvores podem ser encontradas no maciço 5, com média igual a 35,61 metros.

Quanto a altura da primeira ramificação nota-se que o maciço com a média de altura da $1^{\text {a }}$ ramificação mais elevada é o maciço 2 , sendo de 9,25 metros, e o com a média mais baixa é o maciço 5, apresentando média de altura da $1^{\text {a }}$ ramificação de 4,52 metros.

Por fim, o maciço que apresentou média mais alta de PAP para as árvores cadastradas foi o 8, com 2,97 metros, e a média mais baixa de PAP é a do maciço 4 , o qual apresenta média de 1,44 metros. 
Tabela 2. Dimensões das árvores cadastradas.

\begin{tabular}{ccccccccc}
\hline Dimensões $(\mathrm{m})$ & Mac. 1 & Mac. 2 & Mac. 3 & Mac. 4 & Mac. 5 & Mac. 6 & Mac. 7 & Mac. 8 \\
\hline Altura geral & 31,89 & 36,76 & 32,28 & 29,79 & 25,61 & 35,40 & 37,36 & 33,00 \\
Altura 1 ${ }^{\mathrm{a}}$ ram. & 9,25 & 9,67 & 8,27 & 7,51 & 4,52 & 8,48 & 7,90 & 7,57 \\
CAP & 2,05 & 2,03 & 1,52 & 1,44 & 1,74 & 2,14 & 2,51 & 2,97 \\
\hline
\end{tabular}

Quanto ao estado geral das árvores (Tabela 3), nenhum maciço apresentou árvores que se enquadrassem na categoria ótima. O maciço que apresentou maior porcentagem de árvores no estado considerado bom foi o maciço 2 (25\%), sendo que nos maciços 4, 5, 6 e 7, nenhuma árvore pode ser enquadrada nesta categoria.

Árvores com estado geral regular foram registradas em maior porcentagem no maciço 7 (100\%), sendo que no maciço 5 apenas 52\% das árvores cadastradas foram consideradas em estado geral regular. O estado geral péssimo foi observado em maior quantidade $(32,43 \%)$ no maciço 8 , e em menor no maciço 7 , onde nenhum indivíduo se encontrava em estado geral classificado como péssimo. Em todo o levantamento só foram registradas árvores mortas nos maciços 5 (4\%) e 3 (1,18\%).

Tabela 3. Estado geral das árvores cadastradas.

\begin{tabular}{ccccccccc}
\hline Estado (\%) & Mac. 1 & Mac. 2 & Mac. 3 & Mac. 4 & Mac. 5 & Mac. 6 & Mac. 7 & Mac. 8 \\
\hline Ótimo & 0 & 0 & 0 & 0 & 0 & 0 & 0 & 0 \\
Bom & 7,19 & 25 & 9,47 & 0 & 0 & 0 & 0 & 2,38 \\
Regular & 87,41 & 60,89 & 75,74 & 93,33 & 52 & 87,09 & 100 & 76,19 \\
Péssimo & 3,96 & 12,82 & 12,43 & 6,66 & 44 & 12,90 & 0 & 32,43 \\
Morta & 0 & 0 & 1,18 & 0 & 4 & 0 & 0 & 0 \\
\hline
\end{tabular}

Quanto ao equilíbrio das árvores do parque (Tabela 4), o maciço que apresentou a maior quantidade de árvores equilibradas foi o 4 (40\%), e o que apresentou menor número de árvores equilibradas foi o maciço $6(12,90)$, conseqüentemente, no total temos que o maciço 4 apresentou menos árvores desequilibradas (60\%) e o maciço 6 apresentou maior número $(87,10 \%)$.

Nestes maciços, os quais apresentaram valores extremos para este parâmetro, temos que a porcentagem de árvores desequilibradas no caule no maciço 4 é de $23,33 \%$ e na copa $60 \%$, já no maciço, 6 as árvores desequilibradas no caule perfazem o total de $67,74 \%$ e na copa $80,64 \%$.

Por fim, o maciço que apresentou valores maiores de desequilíbrio no caule $(67,74 \%)$ e na copa $(80,64 \%)$ foi o 6 , e os menores valores de desequilíbrio no caule $(23,33 \%)$ foram registrados no maciço 4 e na copa $(58,99 \%)$ no maciço 1. 
Tabela 4. Equilíbrio geral das árvores cadastradas.

\begin{tabular}{lccccccccc}
\hline \multicolumn{2}{c}{ Equilíbrio (\%) } & Mac. 1 & Mac. 2 & Mac. 3 & Mac. 4 & Mac. 5 & Mac. 6 & Mac. 7 & Mac. 8 \\
\hline Equilibrada & & 23,38 & 25,64 & 21,89 & 40 & 18 & 12,90 & 14,28 & 14,28 \\
Desequilibrada & Caule & 58,27 & 33,33 & 36,09 & 23,33 & 40 & 67,74 & 57,14 & 61,90 \\
& Copa & 58,99 & 66,02 & 71,59 & 60 & 76 & 80,64 & 71,43 & 78,57 \\
& Total & 75,18 & 72,43 & 76,92 & 60 & 82 & 87,10 & 85,72 & 85,72 \\
\hline
\end{tabular}

Sobre a fitossanidade das árvores cadastradas, algumas variáveis constantes na ficha, (Figura 1), não foram analisadas por não serem facilmente identificadas em campo, e não terem sido realizadas coletas de material para análise posterior em laboratório.

Dentre os parâmetros analisados temos que, problemas com broca, cupim (Figura 3. a, b, c, d), e fungos são mais freqüentes dentre as árvores estudadas. Sendo assim, o maciço no qual foi registrada a maior ocorrência de brocas foi o maciço 2 (44,23\%), e a menor ocorrência de broca foi registrada no maciço 8 (16,66\%). Danos provocados por cupins foram mais freqüentes nos maciços 4, 5, 6 e 7, os quais apresentaram 100\% dos indivíduos cadastrados com sinais da presença destes insetos, e a menor ocorrência de cupins foi encontrada no maciço 2 (71,15\%).

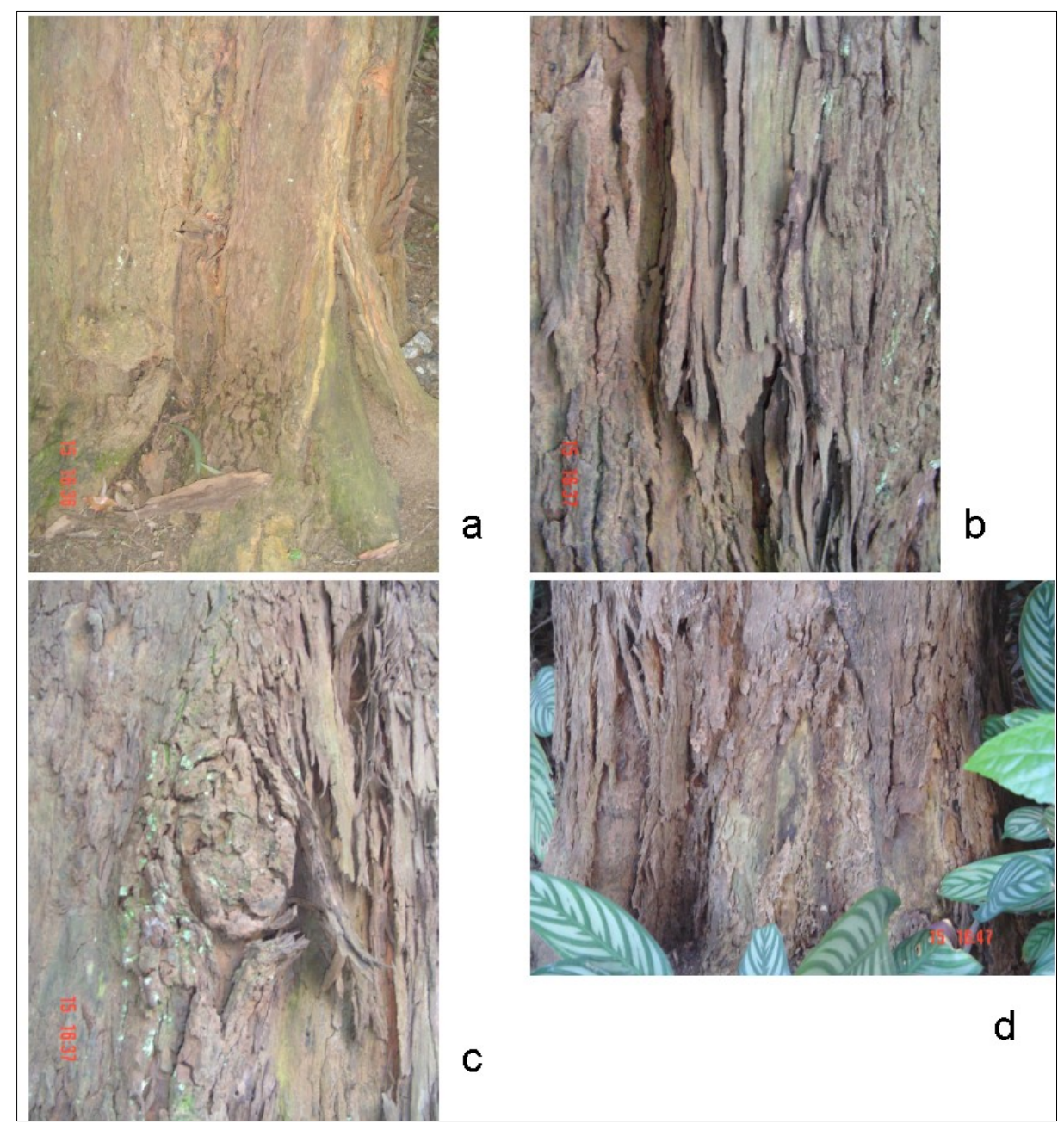

Figura 3 (a, b, c e d). Danos provocados por cupins. 
A presença de formigas como agentes causadores de problemas fitossanitários foi registrada apenas nas árvores dos maciços 1 (5,04\%) e 2 (8,33\%). Insetos de diferentes etiologias, provocando danos nas árvores, foram verificados em maior freqüência no maciço $1(10,07 \%)$ e em menor freqüência nos maciços 5 e 7, os quais não registraram a presença de insetos.

Finalmente, também foram encontrados sinais de fungos, os quais se apresentaram em maior freqüência nos indivíduos do maciço 1 (76,98\%), e em menor no maciço 7 , no qual não foi diagnosticada a presença de fungos.

Referente à intensidade do ataque registrado nas árvores cadastradas (Tabela 5), dentre os maciços analisados aquele que apresentou maior freqüência de ataques de intensidade leve foi o 2 e o que apresentou menor foi o 5, 20,52\% e $0 \%$ respectivamente. Ataques considerados de intensidade média foram registrados em maior quantidade no maciço 4 (43,33\%) e em menor no maciço 6 (12,90\%). A intensidade de ataque pesada foi encontrada em mais árvores no maciço 5 (86\%) e ocorreu em menos árvores no maciço 2 $(43,59 \%)$. A intensidade de ataque classificada como ausente só foi registrada no maciço 1 $(0,36 \%)$.

Tabela 5. Intensidade do ataque provocado pelos diversos agentes identificados nas árvores cadastradas.

\begin{tabular}{ccccccccc}
\hline Intensidade & Mac. 1 & Mac. 2 & Mac. 3 & Mac. 4 & Mac. 5 & Mac. 6 & Mac. 7 & Mac. 8 \\
\hline Leve & 5,04 & 20,51 & 18,93 & 6,66 & 0 & 16,13 & 0 & 14,28 \\
Média & 17,99 & 29,49 & 31,95 & 43,33 & 14 & 12,90 & 14,28 & 21,43 \\
& & & & & & & & \\
Pesada & 74,46 & 43,59 & 49,11 & 50 & 86 & 70,96 & 85,71 & 64,28 \\
Ausente & 0,36 & 0 & 0 & 0 & 0 & 0 & 0 & 0 \\
\hline
\end{tabular}

Quanto ao local onde os agentes causadores de problemas relacionados ao estado fitossanitário das árvores cadastradas (Tabela 6), verifica-se que o local mais afetado das árvores de todos os maciços estudados é o caule, já que para todos os maciços este local é apontado como mais de $90 \%$ de ocorrência de ataque.

Ataques localizados na raiz apresentam maior freqüência no maciço 1 (53,24\%) e menor freqüência nos maciços 4 e 7 , os quais no apresentaram ataques nesta parte dos indivíduos.

Ataques localizados nos frutos*, flores* e ramos* não foram analisados devido a dificuldade de realizar análise visual nestas regiões, ou pela não ocorrência de parte reprodutiva em alguns indivíduos no momento da coleta dos dados.

A ocorrência de ataque nas folhas das árvores foi registrada em maior freqüência no maciço 5 (22\%) e em menor freqüência no maciço 7 , no qual não foi registrado ataque nesta região das árvores cadastradas. 
Tabela 6. Local de ataque do agente identificado nas árvores cadastradas.

\begin{tabular}{ccccccccc}
\hline Local & Mac. 1 & Mac. 2 & Mac. 3 & Mac. 4 & Mac. 5 & Mac. 6 & Mac. 7 & Mac. 8 \\
\hline Caule & 97,48 & 94,87 & 99,41 & 100 & 100 & 100 & 100 & 100 \\
Raiz & 53,24 & 2,56 & 0,59 & 0 & 8 & 9,68 & 0 & 9,52 \\
Frutos* $^{*}$ & 0 & 0 & 0 & 0 & 0 & 0 & 0 & 0 \\
Flores* $^{*}$ & 0 & 0 & 0 & 0 & 0 & 0 & 0 & 0 \\
Ramos $^{*}$ & 0 & 0 & 0 & 0 & 0 & 0 & 0 & 0 \\
Folhas & 8,27 & 8,33 & 7,10 & 3,33 & 22 & 12,90 & 0 & 9,52 \\
\hline
\end{tabular}

As lesões de intensidade grave foram, quando comparadas aos outros graus de lesões as que se destacaram mais (Tabela 7), ocorrendo em maior freqüência nas árvores do maciço 5 (88\%) e em menor no maciço 1 (34,39). Já as lesões médias ocorreram em maior número nos indivíduos do maciço 7 (28,57\%) e em menor no maciço 5 (12\%). As lesões leves foram mais freqüentes no maciço $2(13,46 \%)$ e menos freqüentes nos maciços 5 e 7, ambos com 0\%. As lesões estão ausentes em 16,19\% das árvores do maciço 1, sendo este o maciço que apresentou maior número de indivíduos com esta classificação, e nenhuma árvore dos maciços 4, 5, 6 e 7 apresenta esta classificação, ou seja, todas as árvores destes maciços apresentam algum grau de lesão. Por último o vandalismo pode ser encontrado com maior freqüência nas árvores do maciço 4 (56,66\%) e em menor nas árvores do maciço 1 (21,22\%).

Tabela 7. Intensidade das lesões das árvores cadastradas.

\begin{tabular}{ccccccccc}
\hline Lesões (\%) & Mac. 1 & Mac. 2 & Mac. 3 & Mac. 4 & Mac. 5 & Mac. 6 & Mac. 7 & Mac. 8 \\
\hline Grave & 34,39 & 58,97 & 55,62 & 63,33 & 88 & 67,74 & 71,42 & 71,42 \\
Média & 26,62 & 13,46 & 27,21 & 26,66 & 12 & 12,9 & 28,57 & 16,66 \\
Leve & 12,59 & 13,46 & 11,83 & 6,66 & 0 & 12,90 & 0 & 7,14 \\
Ausente & 16,19 & 0,64 & 0,59 & 0 & 0 & 0 & 0 & 2,38 \\
Vandalismo & 21,22 & 50 & 55,02 & 56,66 & 30 & 38,70 & 42,86 & 23,80 \\
\hline
\end{tabular}

Para a relação ecológica das árvores cadastradas das árvores (Tabela 8), as presenças de liquens e epífitas foram as mais relevantes. O maciço que mais apresentou liquens foi o 4 (90\%) e o que menos apresentou foi o 7 (28,57\%), já as epífitas aparecem em maior freqüência também no maciço 4 (33,33\%) e em menor no maciço 5 (6\%). No que tange os insetos o maciço que apresentou maior número de indivíduos nos quais havia a presença daqueles foi o maciço $2(10,92 \%)$ e o maciço 7 não apresentou registros de insetos nos indivíduos cadastrados. Os ninhos estiveram presentes apenas em árvores dos maciços $1(2,52 \%)$ e $3(0,59 \%)$. 
Tabela 8. Relações ecológicas das árvores cadastradas.

\begin{tabular}{ccccccccc}
\hline Ecologia (\%) & Mac. 1 & Mac. 2 & Mac. 3 & Mac. 4 & Mac. 5 & Mac. 6 & Mac. 7 & Mac. 8 \\
\hline Insetos & 5,76 & 10,92 & 7,69 & 10 & 4 & 6,45 & 0 & 4,76 \\
Ninhos & 2,52 & 0 & 0,59 & 0 & 0 & 0 & 0 & 0 \\
Liquens & 42,81 & 34,61 & 77,51 & 90 & 34 & 51,61 & 28,57 & 45,24 \\
Epífitas & 9,71 & 18,59 & 20,71 & 33,33 & 6 & 12,90 & 14,28 & 7,14 \\
Parasitas & 7,55 & 1,28 & 0,59 & 0 & 2 & 6,45 & 0 & 7,14 \\
\hline
\end{tabular}

A caracterização do estado fenológico das árvores do parque foi feita apenas com análise visual sem o auxílio de nenhum aparelho, o que pode ter prejudicado a avaliação devido às elevadas alturas das copas de alguns indivíduos.

Todos os maciços, com exceção do 3 e do 5, onde foram registradas árvores mortas, apresentaram folhas, o que já era de se esperar pois o Eucalipto é uma espécie perenifólia. Quanto a floração, o maciço onde foi registrada maior presença de flores foi o $1(21,22 \%)$ e o que menos apresentou flor foi o maciço 4, onde elas não foram registradas. Os frutos aparecem com mais freqüência no maciço $7(85,71 \%)$ e em menor freqüência no maciço 1 $(23,74 \%)$.

Como evidenciado na fotografia do parque (Figura 4), os maciços 5, 6 e 8 estão localizados no borda do parque enquanto os outros, em seu interior. O maciço que mais apresentou indivíduos localizados junto à guia foi o $8(19,04 \%)$ e o que menos apresentou esta característica foi o 6 onde não foram registrados nenhum indivíduo nestas condições. Sendo assim, no maciço 6 todas as árvores estão no interior do bosque (Tabela 9).

Portanto o maciço 6 não apresenta afloramento de raiz provocando danos à calçada, leito carroçável ou construção. Para estas características os maciços mais representativos foram o $7(14,28 \%)$, o 8 (9,52\%) e o $2(4,48 \%)$, respectivamente.

Tabela 9. Situação do entorno das árvores avaliadas.

\begin{tabular}{cccccccccc}
\hline Entorno & & M. 1 & M. 2 & M. 3 & M. 4 & M. 5 & M. 6 & M. 7 & M. 8 \\
\hline Localização & Borda & 0 & 0 & 0 & 0 & 100 & 100 & 0 & 100 \\
no parque & Interior & 100 & 100 & 100 & 100 & 0 & 0 & 100 & 0 \\
\hline \multirow{2}{*}{ Localização relativa } & Junto à guia & 12,2 & 15,3 & 4,73 & 16,6 & 12 & 0 & 14,2 & 19,0 \\
& No bosque & 87,7 & 84,6 & 95,2 & 83,3 & 88 & 100 & 85,7 & 80,9 \\
\hline \multirow{2}{*}{ Afloramento } & Calçada & 1,44 & 3,20 & 1,77 & 13,3 & 8 & 0 & 14,2 & 7,14 \\
de raiz & Construção & 0 & 0 & 0 & 0 & 0 & 0 & 0 & 9,52 \\
& Leito Carroç. & 1,08 & 4,48 & 0 & 0 & 0 & 0 & 0 & 2,38 \\
\hline \multirow{2}{*}{ Tipo de uso } & Recreativo & 64,0 & 0 & 0 & 0 & 100 & 100 & 100 & 100 \\
& Contemplat. & 100 & 100 & 100 & 100 & 100 & 100 & 100 & 100 \\
\hline
\end{tabular}

Elaborou-se diagramas de dispersão e equações de regressão polinomial para melhor correlacionar as variáveis mensuradas com a localização de cada maciço (Figura 4). 


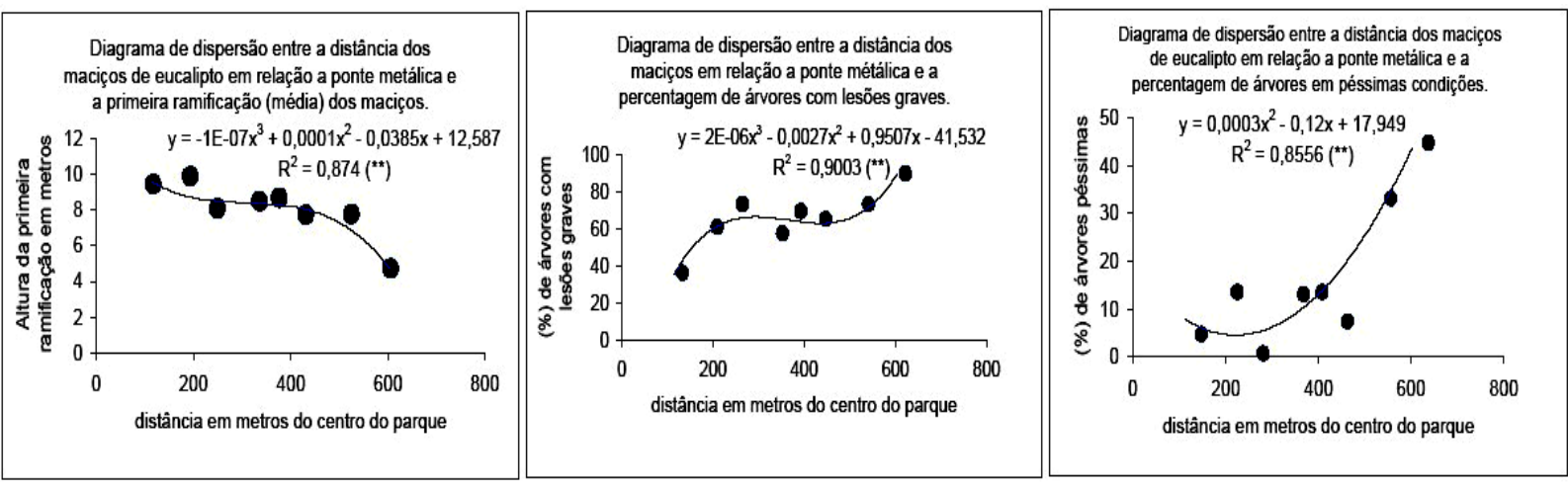

Figura 4. Diagramas de dispersão entre a distância dos maciços do centro do parque (obtidas pelo SIG) e as variáveis altura da 1 a ramificação, lesões graves e condição péssima. Os valores de $\mathrm{R}^{2}$ foram significativos pelo Teste t a $1 \%$ de probabilidade.

Pode se notar que os maciços à medida que estão mais próximos da borda do parque, ou distantes do centro, estão mais afetados por lesões graves, estão com maior número de árvores em péssimas condições e possuem menores alturas da $1^{\mathrm{a}}$ ramificação. Esse último fator pode estar indicando que os maciços mais próximos da borda (longe do centro) são mais iluminados e assim os galhos mais baixos ainda são úteis e produtivos. Isso pode acontecer devido a maior queda de árvores ou uma maior quantidade de podas de rebaixamento que são efetuadas para garantir a segurança do entorno do parque, constituído por avenidas de alta circulação de veículos e imóveis de alto padrão, provavelmente mais quentes do que o interior do parque. CREGG et al. (2001) encontraram relação entre ilhas de calor urbanas e o aumento de pragas em árvores na cidade de Lincoln, Nebraska, U.S. e concluíram que os fatores temperatura alta e baixa umidade devem ser avaliados como possíveis causadores de estresse arbóreo. É nítido, portanto, o efeito de borda, caracterizando o estresse urbano como elemento causador do declínio.

O conceito de declínio pode ser representado em uma espiral na qual a poluição atmosférica produzida pela intensa circulação de veículos automotivos, luzes noturnas e podas devido ao contato com equipamentos urbanos são fatores de predisposição para doenças que nada mais são do que expressão da debilidade causada pelo meio (MILANO \& DALCIN, 2000).

No geral o contato com a fiação pode ser considerado irrelevante já que o número de árvores sem contato com afiação para todos os maciços foi superior a 95\%, sendo a única exceção o maciço 8 com 92\%.

Por último o maciço que foi considerado como tendo mais árvores em situação adequada foi o 7 (100\%) e o que menos possuía árvores em situação adequada foi o 3 $(38,46 \%)$.

Com relação às ações de manejo executadas, como é de conhecimento prévio, não são executadas, já que não é realizado um manejo dos maciços de Eucalipto, a não ser no 
que diz respeito à poda. Com relação ao plantio, somente são plantados, nos maciços de Eucalipto, indivíduos arbóreos de outras espécies, com a finalidade de uma lenta e gradual substituição daqueles por essências nativas. Quanto ao aspecto de verticalidade, associado ao conceito paisagístico dos maciços, a argumentação é de que as árvores plantadas no sub-bosque crescerão com o fuste reto não interferindo neste aspecto, porém a questão histórica não é levada em consideração.

O maciço que mais registrou podas leves foi o 7 (14,28\%) não sendo registradas nos maciços 4 e 6. Quanto às podas pesadas, a maior freqüência ocorre no maciço 5 (38\%) não sendo registradas nos maciços 4 e 7 . A qualidade da ação avaliada engloba todos os tipos de ação verificada, porém é importante ressaltar que quando forem de péssima qualidade, a ação a que se referem é a poda pesada na maioria dos casos.

A poda pesada observada no parque diz respeito às podas de rebaixamento (Figura 5). Esse tipo de poda é realizado com o intuito de minimizar o risco de queda de árvores que estão em condição não adequada (muito inclinada ou não sadia, e portanto, oferecendo risco aos usuários). Esta prática foi considerada péssima por ser entendida como uma técnica de manejo não adequado que só irá postergar o problema já que o Eucalipto rebrota e muitas destas árvores poderão, em um futuro próximo, continuar sendo classificadas como potencialmente perigosas. Outro argumento utilizado é o de que a burocratização, devido aos processos de tombamento da vegetação do parque, impede que medidas urgentes sejam tomadas.

Dentre as ações recomendadas a que possui maior freqüência de indivíduos, em todos os maciços, é a substituição. Essa ação reflete o péssimo estado das árvores do parque, como visto até o momento, bem como indivíduos que não se encontram em local adequado (margem do córrego, junto das guias, provocando danos às construções, etc.), sendo necessário então proceder com sua remoção. 


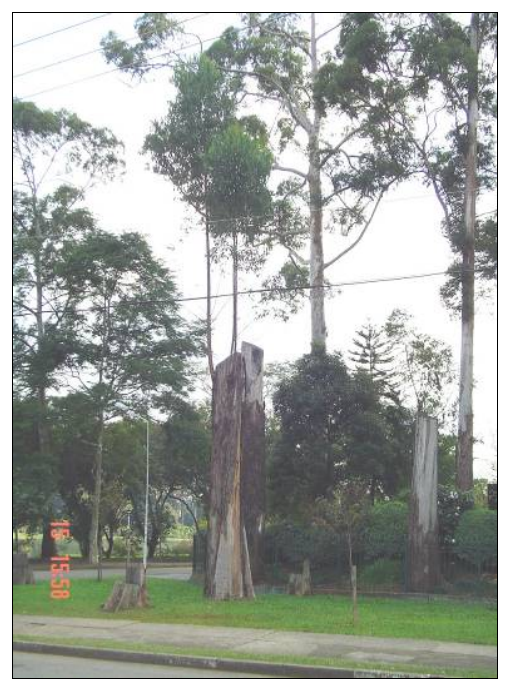

Figura 5. Podas de rebaixamento.

Dentre todos os maciços o que apresenta maior freqüência de árvores para serem substituídas é o maciço 7 (100\%) e os maciços que precisam de menos substituição são o 2 e 3 , ambos com $38,46 \%$ dos indivíduos a serem substituídos.

Durante o momento da coleta de dados sobre as árvores também foi avaliado o tipo de uso destinado a cada maciço enquanto recreacional ou contemplativo. Assim, o maciço 1 apresentou os dois tipos de uso, enquanto os maciços 2, 3 e 4 foram classificados apenas como sendo de uso contemplativo e os maciços 5, 6, 7 e 8 classificados como sendo tanto de uso recreativo quanto contemplativo.

Ainda com relação a integridade física dos troncos de eucalipto os registros de resistência a penetração do resistógrafo estão na figura 6. Pode-se visualizar áreas de baixa resistência a penetração caracterizando tecido em decomposição e com baixa resistência a esforços de tração e compressão e podendo indicar problemas nas raízes dessas árvores. Segundo COSTELO \& QUARLES (1999) quando as árvores possuem baixa resistência a penetração em mais de dois terços do diâmetro do tronco deve-se permitir sua substituição. 


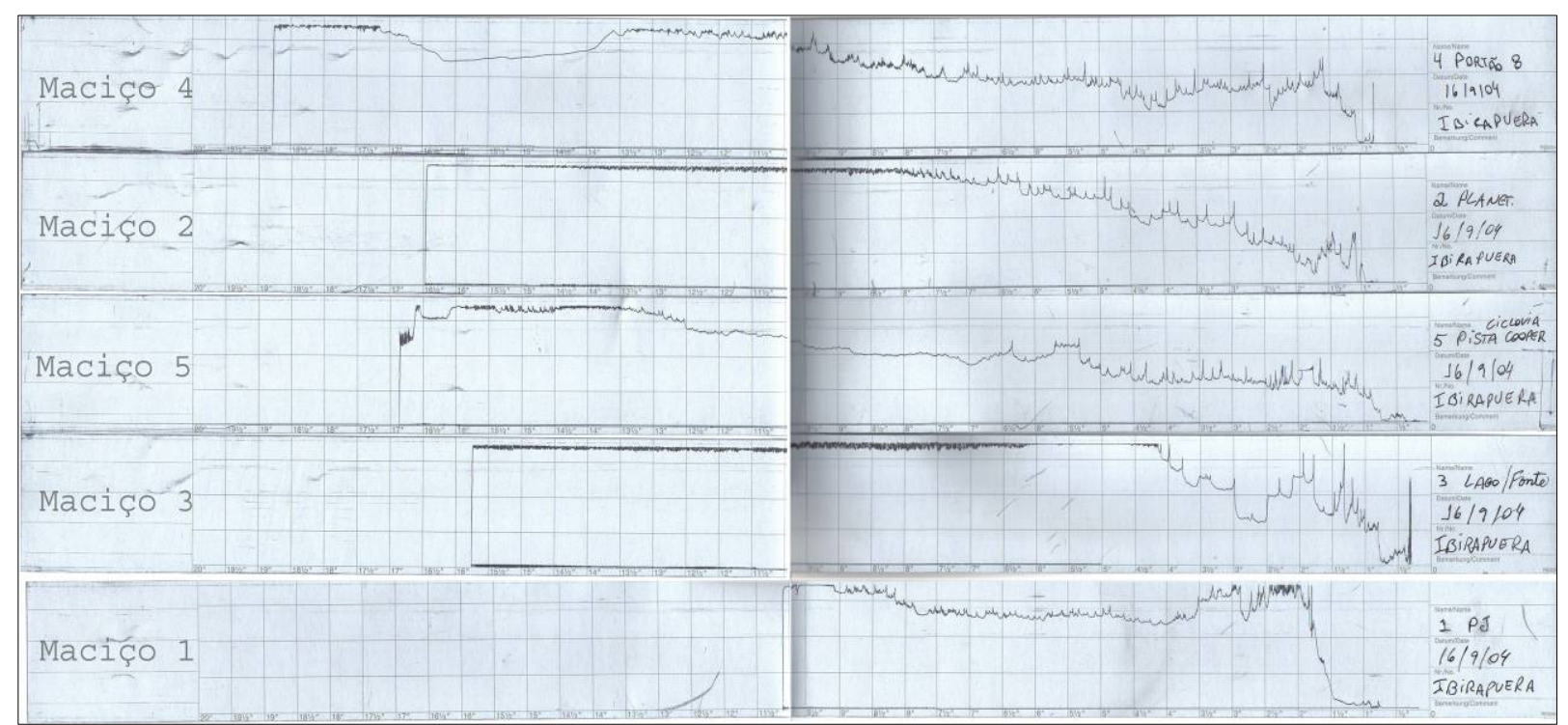

Figura 6. Registro de resistência a penetração do resistógrafo e cinco árvores de eucalipto do Parque Ibirapuera, os maciços a qual pertence cada árvore estão do lado esquerdo.

Pela observação da figura 6, a árvore do maciço 1 apresentou boa resistência durante toda a perfuração porém as árvores dos outros maciços apresentam áreas com elevada resistência e áreas com muito baixa resistência indicando serem essas áreas de baixa resistência as que possuem tecidos em decomposição. As melhores leituras ocorreram nas árvores dos maciços 1 e 3 e as piores nas árvores dos maciços 4 e 5 com tecidos de baixa resistência porém não atingindo mais de dois terços do diâmetro do tronco.

\section{Classificação das imagens}

Aerofotografia do Parque Ibirapuera

Com relação às quantificações elaboradas a partir da imagem do Parque Ibirapuera obteve-se os dados contidos na tabela 10. As estatísticas Kappa e exatidão geral obtida da matriz de erro da classificação supervisionada estão na figura 7 e comprovam a exatidão do mapeamento como excelente, 80 a 100\% (LANDIS \& KOCH, 1977). 
Tabela 10. Área dos elementos estruturais do parque Ibirapuera.

\begin{tabular}{cccc}
\hline Elemento & Área $\left(\mathrm{m}^{2}\right)$ & Elemento & Área $\left(\mathrm{m}^{2}\right)$ \\
\hline Viveiro Manequinho Lopez & $85.055,15$ & Maciço 3 & $9.314,18$ \\
Planetário e Escola de & 2.100 & Maciço 4 & $13.078,68$ \\
Astrofísica & & Maciço 5 & $22.386,53$ \\
Pavilhão Japonês & $7.426,02$ & Maciço 6 & 29.421 \\
Fundação Bienal & 13.038 & Maciço 7 & $8.489,77$ \\
Fundação Brasil Connects (OCA) & $4.673,79$ & Maciço 8 & $26.341,82$ \\
Pavilhão Manoel da Nóbrega & 6.600 & Área total dos Eucaliptos & $175.855,10$ \\
Prodam & 6.500 & Área Gramada & $193.477,81$ \\
Marquise & $28.411,08$ & Área dos indivíduos & $61.270,08$ \\
Superfície Total dos Lagos & $125.591,90$ & arbóreos* & \\
Área coberta por pavimento & $44.668,36$ & Área total vegetada & $430.602,99$ \\
Maciço 1 & $57.450,91$ & Área total do Parque & $1.276 .238,87$ \\
Maciço 2 & $9.372,21$ & & \\
\hline
\end{tabular}

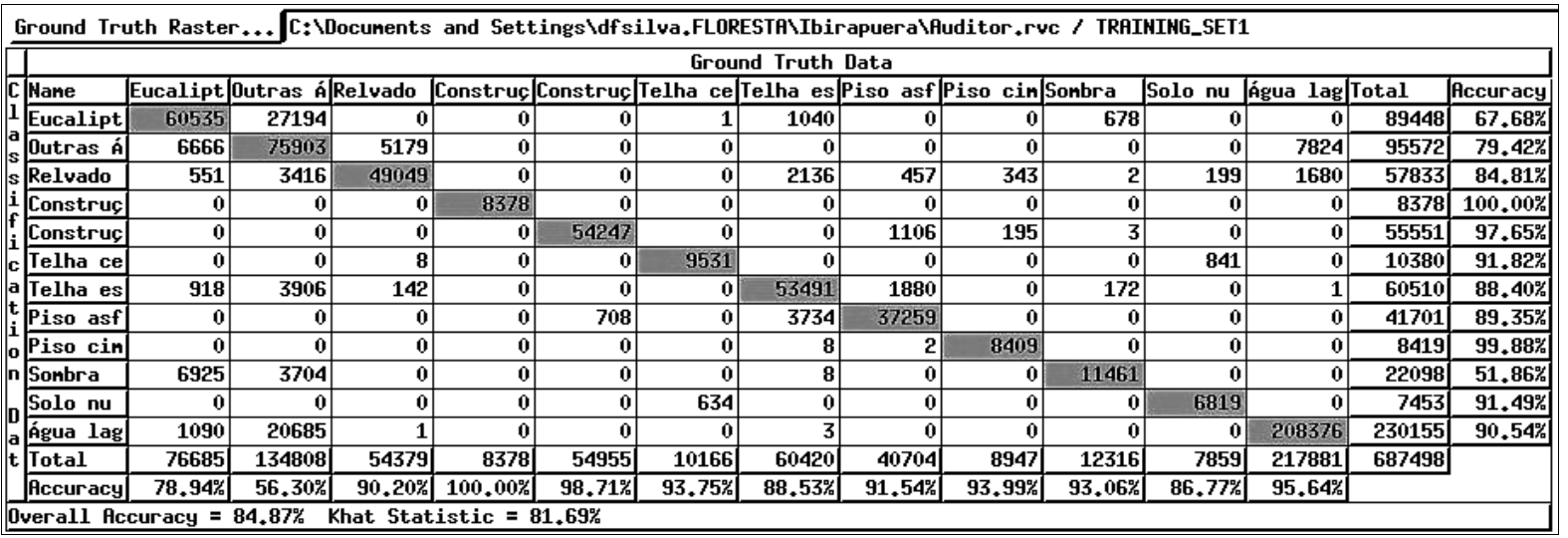

Figura 7. Matriz de erro da classificação supervisionada do Parque Ibirapuera obtida no ambiente do sistema de informações geográficas TNT Mips.

Analisando a paisagem do parque do ponto de vista quantitativo, observa-se uma boa proporção entre estruturas urbanas e vegetação garantindo bom equilíbrio climático para as áreas internas do parque, o que pode explicar os melhores resultados obtidos pelos maciços mais próximos do centro do parque, (Tabela 10).

Muito embora o índice Kappa tenha sido excelente, as imagens fotográficas digitais coloridas obtiveram erros de mensuração com exceção da classe construções. Os maiores erros foram detectados para as classes "Outras árvores" e "Sombra" e os maciços de eucalipto também estão confundindo com "Outras árvores". Com o uso de imagens infravermelhas será possível melhorar a classificação devido a maior refletância nesta faixa do espectro. Observa-se que as áreas vegetadas, especialmente os maciços de eucalipto, superam as áreas construídas e pavimentadas, constituindo elementos estruturadores da paisagem do parque. 


\section{CONCLUSÕES}

Por meio dos métodos usados e resultados encontrados é possível afirmar que:

As imagens provenientes de aerofotografia colorida de alta resolução foram suficientes para obtenção de dados e análise dos maciços do parque e suas relações com os demais componentes do entorno.

Os maciços de eucalipto do Parque Ibirapuera estão em declínio e necessitam de manejo para reposição de árvores e adequação aos locais.

O declínio dos maciços está associado com o estresse causado pelo ambiente urbano, caracterizando uma variável para ser trabalhada no manejo do parque.

O efeito de borda encontrado é um dos fatores responsáveis pelo estresse das árvores do gênero eucalipto. Esse conhecimento pode nortear políticas públicas com objetivo de criar desenhos de vegetação para servir de área de amortecimento, protegendo a biota do parque.

A continuação das pesquisas com a ampliação das análises para outros componentes da vegetação poderão ampliar o conhecimento sobre as inter-relações das diferentes formas de vegetação e os demais componentes urbanos.

Indica-se a ampliação da diversidade dos maciços como forma de melhorar sua resistência aos efeitos nocivos da poluição e demais fatores estressantes para a vegetação.

\section{REFERÊNCIAS BIBLIOGRÁFICAS}

AUER, C.G. Doenças de árvores urbanas. Colombo: EMBRAPA-CNPF, 1996. 18p. (EMBRAPA-CNPF. Documentos, 28).

CREGG, B.M. \& DIX, M.E. Tree moisure stress and insect damage in urban areas in relation to heat island effects. Journal of Arboriculture, v. 27(1), p.8-17, 2001.

COSTELLO, L.R. \& QUARLES, S.L. Detection of wood decay in Blue gum and Elm: an evaluation of the resistograph and the portable drill. Journal of Arboriculture, v. 25(6), p.311-318, 1999.

DEPAVE-CPHN. Conhecendo o Verde: Parque Ibirapuera. N.11, 22p., 1988.

HERMY, M. \& CORNELIS, J. Towards a monitoring method and a number of multifaceted and hierarchical biodiversity indicators for urban and suburban parks. Landscape and Urban Planning, v. 49, p.149-162, 2000. 
KLIASS, R.G. Parques Urbanos de São Paulo e sua evolução na cidade. São Paulo, SP: Pini, 1993. 211p.

LANDIS, J.R.; KOCH, G.G. The measurement of observer agreement for categorical data. Biometrics, Arlington, v.33, n.1, p.159-174, 1977.

METZGER, J. P. Estrutura da paisagem e fragmentação: Análise bibliográfica. Anais da Academia Brasileira de Ciências. 1999, 71 (3-1), 445 - 463.

MILANO, M.S.; DALCIN, E.C. Arborização de vias públicas. Rio de Janeiro, RJ: Light, 2000. 226 p.

SILVA, A.M. Ecologia da Paisagem - Fundamentos e Aplicações. Rio de Janeiro, RJ: Papel Virtual Editora. 2004. 157p.

SILVA FILHO, D.F. da. Cadastramento informatizado, sistematização e análise da arborização das vias públicas da área urbana do Município de Jaboticabal, SP. 2002. 81 f. Dissertação (Mestrado em Agronomia) - Faculdade de Ciências Agrárias e Veterinárias, Universidade Estadual Paulista, Jaboticabal, 2002.

SMITH, R.B. Getting Started: Image Classification with TNT mips. Lincoln, Nebraska, Microimages, Inc, 2000. 36 p.

VEIGA, A.P.B. Avaliação dos maciços de eucalipto e sua relação com o entorno no Parque Ibirapuera. 2004. 68 f. Relatório de Estágio Profissionalizante (Engenharia Florestal) - Escola Superior de Agronomia "Luiz de Queiroz", Universidade de São Paulo, Piracicaba, 2004. 